\title{
Firmalarda Sahiplik Yapısı İle Kâr Dağıtım Politikası Arasındaki İlişkinin Incelenmesi: Borsa İstanbul'da Bir Uygulama $^{1}$
}

\author{
Relationship between Dividend Policy and Ownership Structure in Emerging \\ Markets: An Application in Borsa Istanbul
}

\author{
Ahmet AKUSTA* \\ Mehmet Nuri SALUR**
}

$\ddot{O} Z$

Kâr dağıtım politikası son yıllarda sık araştırılan bir finans konusudur. Kâr dă̆ıtımı kurumsal yönetim ve finansal yönetim açısından oldukça önemlidir. Şirketler için de önemli bir finans kaynağı olabilen dă̆ıtılmamış kârlar, şirketin sahiplik yapısından etkilenmektedir. Sahiplik yapısı ile kâr dă̆ıtım politikası arasındaki ilişkiyi tespit etmek amacıyla BIST 50 Endeksinde kayıtl şirketlerin 2015-2016-2017 yılları sahiplik yapıları ve finansal verileri incelenmiştir. Gerçekleştirilen panel veri analizi sonuçları ayrıntılı şekilde raporlanmıştır. Elde edilen bulgular BİST 50 endeksinde kayıtlı 2015-2016-2017 yıllarında kâr dă̆ıtımı yapmışşirketlerde sahip yoğunluğu ile kâr dă̆ıtımı arasında negatifyönlü ilişki tespit edilmiştir.

\section{ANAHTAR KELIMELER}

Kâr Dă̆ıtım Politikası, Sahiplik Yapısı, Sahiplik Yoğunluğu, Halka Açıklık Oranı, En Büyük Ortak

\begin{abstract}
Dividend Policy is a frequently discussed finance issue in recent years. Dividend payout is very important in terms of corporate governance and financial management. Retained profits, which can be an important financial source for companies, are also affected by the ownership structure of the company. In order to determine the relationship between the ownership structure and the dividend policy, the ownership structures and financial data of the companies registered in the BIST 50 Index for the years 2015-2017 were studied. The results of the panel data analysis were reported in detail. The findings showed that among the companies registered BIST 50 Index in 2015-2016-2017 years which distributed profit, have a negative relationship between the density of the dividend payout.
\end{abstract}

KEYWORDS

Dividend Policy, Ownership Structure, Ownership Density, Free Float Ratio, Largest Shareholder

\begin{tabular}{|c|c|c|}
\hline \multicolumn{2}{|r|}{$\begin{array}{l}\text { Makale Geliş Tarihi / Submission Date } \\
20.11 .2019\end{array}$} & $\begin{array}{c}\text { Makale Kabul Tarihi / Date of Acceptance } \\
22.04 .2020\end{array}$ \\
\hline Attf & $\begin{array}{l}\text { Akusta, A. ve Salur, M.N. (2020). I } \\
\text { İncelenmesi: Borsa İstanbul'da Bir Uyః } \\
153 \text {. }\end{array}$ & $\begin{array}{l}\text { Ipı1 İle Kâr Dağııı Politikası Arasındaki İlişskinin } \\
\text { itesi Sosyal Bilimler Meslek Yüksekokulu Dergisi, 141- }\end{array}$ \\
\hline
\end{tabular}

\footnotetext{
${ }^{1}$ Bu çalışma “Gelişen Piyasalarda Kâr Dağıtım Politikası ve Sahiplik Yapısı Arasındaki İlişki: Borsa İstanbul'da Bir Uygulama” başlıklı Yüksek Lisans Tezinden türetilmiştir.

* Öğr. Gör., Konya Teknik Üniversitesi, Rektörlük, ahmetakusta@hotmail.com, ORCID: 0000-0002-5160-3210

** Dr. Öğr. Üyesi, Necmettin Erbakan Üniversitesi, Siyasal Bilgiler Fakültesi, İşletme Bölümü, nsalur@erbakan.edu.tr, ORCID: 0000-0003-1089-1372
} 


\section{GİRIŞ}

Genel anlamda sahiplik, sosyolojik ve hukuki bir kavramdır. Sahiplik kavramı Türk Dil Kurumu tarafindan “... kendisinin olan bir şeyi yasalar çerçevesinde dilediği gibi kullanabilme hakkl” olarak tanımlamıştır (http://www.tdk.gov.tr). Finansal anlamda sahiplik denildiğinde ise sermaye sahipliği akla gelmektedir. Sermaye, işletmeye konulan öz kaynaklardan ve borçlardan oluşmaktadır (Önem, 2014: 30).

Sahiplik yapısı işletmeler açısından önemlidir. Zira işletme sahipleri ile yöneticiler farklı kimselerden oluştuğunda temsil maliyetleri ortaya çıkmaktadır. Temsil maliyetlerinden korunmak için çeşitli formüller geliştirilmiştir. Yöneticilere, sahiplik hakkı tanınarak işletmeye olan bağlılıklarını arttırmak suretiyle temsil maliyetlerinin minimize edilmeye çalışılması bunlardan biridir (Davies vd., 2002: 11).

Kâr dağıtımı işletmelerin finansal yönetimi açısından oldukça önemlidir. Kâr dağıtım politikaları, işletmelerin sermaye yatırımlarını-yasal mevzuat dikkate alınarak-içinde bulunulan ekonomik koşullara göre şekillendirmektedir. Örneğin işletme sermaye yatırımları sonucunda dağıtılmamış kârların şirket içinde tutulmasından daha fazla getiri elde ediyorsa dağıtılmamış kârlar aracı olarak kullanılır (Manneh, 2014: 25). Diğer taraftan likidite pozisyonu kuvvetli olan şirketler kârın dağıtılmasına daha olumlu yaklaşırlar (Canbaş ve Vural, 2012:331).

Çalışmada, BİST 50 Endeksi'nde kayıtlı şirketlerin kâr dağıtım politikalarının belirlenmesinde sahiplik yapılarının etkileri araştırılmıştır. Bu kapsamda ilk başta literatür taramasına yer verilmiş, sonrasında yapılan ampirik uygulama ve sonuçlarına değinilmiştir. Çalışmanın sonuç bölümünde ise uygulama sonuçları daha önceki yapılan bazı çalışmaların sonuçlarıyla karşılaştırılarak tartışılmış ve önerilere yer verilmiştir.

\section{LITERATÜR TARAMASI}

Örgün ve Aygün (2018), mülkiyet yapısı ile kâr kalitesi arasındaki ilişkiyi tespit etmek amacıyla Borsa İstanbul'da işlem gören 130 adet firmanın 2014-2015 yılları finansal verilerini analiz etmiştir. Çalışmanın sonucunda kâr kalitesi ile yabancı sahiplik arasında istatistiksel açıdan anlamlı ve pozitif yönde bir ilişki saptanırken diğer değişkenler ile kâr kalitesi arasında anlamlı bir ilişki görülmemiştir.

Ting vd. (2017), sahiplik yoğunluğunun temettü politikasına ve firma performansına etkisini araştırmıştır. Malezyalı halka açık şirketlerin 2005-2015 yılları arasındaki 11 yıllık finansal verilerinden yararlanarak yaptıkları çalışmada sahiplik yoğunlaşması düşük temettü dağıtımına neden olsa da firma performansını arttırdığı sonucuna ulaşmışlardır.

Qahtani ve Ajina (2017), mülkiyet yapısı ve temettü dağıtımı arasındaki ilişkiyi incelemek amacıyla yaptıkları çalışmalarında Suudi Borsası'na kayıtlı 100 şirketin 2012-2015 yılları arasındaki 4 yıllık dönemlerini incelemiştir. Yönetsel sahipliğin temettü dağıtımını artırdığı, aile sahipliği ile dağıtılan temettü miktarı arasında ise negatif korelasyon olduğu tespit edilmiştir. Ayrıca kurumsal sahipliğin artması durumunda yüksek temettü ödemesine gerek kalmadığı da tespit edilmiştir.

Erdaş (2017), 12 farklı sektörde faaliyet gösteren Borsa İstanbul 30 Endeksi'nde bulunan bütün firmaların 2010-2015 yılları arasındaki kâr dağıtım politikalarına etki eden faktörleri araştırmıştır. Araştırma sonuçları işletme büyüklüğü, nakit oranı, hisse başına kazanç, hisse senedinin piyasa değerinin kâr dağıtım oranına pozitif yönde etki ettiğini; finansal kaldıraç oranı ve işletme yaşının karesinin kâr dağıtım oranına negatif yönde etki ettiğini tespit etmiştir.

Lundgren vd. (2016), sahiplik yapısının temettü dağıtım politikası üzerindeki etkilerini incelemek amacıyla İsveç Stockholm Borsası'na kayıtlı, 2010-2015 yılları arasında faaliyet gösteren 284 firma üzerinde 1046 gözlem yapmıştır. Çalışmanın özel amacı yatırımcı türleri ile temettü dağıtım arasındaki ilişkiyi çözmektir. Bağımlı değişken olarak seçilen temettü politikası değişkenleri temettü dağıtım oranı ve temettünün getirisidir. Yaptıkları regresyon analizleri sonucunda kurumsal yatırımcılar ile temettü getirisi ve temettü oranı arasında pozitif ilişki tespit etmişlerdir.

Khan vd. (2016), KSE 100 endeksinde kayıtlı bulunan 50 finansal olmayan şirketin 2006-2014 y1llarını inceledikleri araştırmalarında sahiplik yapısının sermaye yapısı ve temettü politikası üzerindeki etkisini araştırmışlardır. Araştırma sonuçları kurumsal sahipliğinin sermaye yapısı üzerine negatif yönde önemli ölçüde etkisinin olduğunu ve temettü üzerinde pozitif yönde etkisinin olduğunu göstermektedir. Diğer taraftan yönetsel sahipliğin kâr dağıtım oranını negatif yönde etkilediğini sonucuna da ulaşmışlardır.

Reyna (2015), sahiplik yapısının temettü politikasına bir etkisinin olup olmadığını araştırmak amacıyla Meksika Borsası'na kayıtlı şirketlerin 2005-2013 yılları arasındaki 8 dönemlik verilerini kullanarak 675 adet gözlem yapmıştır. Araştırma sonuçlarına göre sahiplik yoğunluğunun yüksek olduğu, aile sahipliğinin temettü ödemeleri ile negatif ilişkisi olduğunu ve kurumsal sahiplik ile temettü ödemesi arasında pozitif ilişki olduğu tespit edilmiştir. 
Ersoy ve Çetenak (2015), sahiplik yoğunlaşmasının kâr dağıtım kararlarına etkisini araştırmak amacıyla Borsa İstanbul' da işlem gören 116 sanayi şirketinin 2004-2009 yılları arasındaki faaliyetlerini rassal etkili tobit ve sistem genelleştirilmiş momentler metodu ile incelemiş̧ir. Kâr dağıtımı yapan firmalar yavaş büyüyen ve yüksek hızla büyüyen firmalar olarak ikiye ayrılmış, yavaş büyüyen firmalarda sahiplik yoğunlaşmasının temettü kararlarına bir etkisinin olmadığı, yüksek hızla büyüyen firmalarda ise temettü kararlarının sahiplik yoğunlaşması, kârlılık ve piyasa değeri tarafindan belirlendiği sonucu ortaya koyulmuştur.

Ghumni vd. (2013), çalışmalarında Ürdün'deki yabancı yatırımcıların özelliklerini araştırmak amacıyla Amman Borsası'na kayıtlı şirketleri incelemişlerdir. Araştırma sonuçlarına göre; Ürdün'deki yabanc1 yatırımcılar düşük temettü dağıtan firmaları seçmektedir. Ayrıca maden çıkarma şirketleri ve inşaat şirketlerinin üretim verimliliği açısından yabancı yatırımcılardan pozitif yönde etkilendiği de tespit edilmiştir.

Arshad vd. (2013), sahiplik yapısı ile kâr dağıtım politikası arasındaki potansiyel ilişkiyi tespit etmek için Karachi Borsası'na kayıtlı şirketlerin 2007-2011 yılları arasındaki verilerini incelemişlerdir. Çalışmada tanımlayıcı istatistikler ve korelasyon analizi kullanılmıştır. Çalışma sonucunda, sahiplik yapısı ile kâr dağıtımı arasında muhtemel bir ilişkinin olmadığ 1 tespit edilmiştir.

Uwigbe (2012), finansal kaldıracın ve sahiplik yapısının temettü ödemeleri üzerindeki etkisini araştırmıştır. Nijerya Borsası'na kayıtlı 50 şirketin 2006-2010 yılları arasındaki finansal tablolarını regresyon analizi yöntemi ile incelemiştir. Gerçekleştirilen analiz sonuçları göre, örneklem olarak seçilen şirketlerde temettü ile sahiplik yapısı arasında pozitif yönlü, finansal kaldıraç arasında ise negatif yönlü ilişki bulunduğunu tespit etmiştir.

Ullah vd. (2012), yaptıkları çalışmada yatırımcılar üzerinde çok büyük etkiye sahip bir kurumsal karar olan sahiplik yapısının belirleyicilerini araştırmışlardır. Karachi Borsası'na kayıtlı KSE 30 Endeksi'nde bulunan firmaların 2003-2010 yılları arasındaki verileri çoklu regresyon yöntemi ile analiz edilmiştir. Elde edilen analiz sonuçlara göre, temettü ödemeleri ile yönetsel sahiplik arasında negatif ilişkinin olduğu, kurumsal sahiplik yabancı sahiplik arasında ise pozitif yönde ilişkinin olduğu belirlenmiştir.

Wei vd. (2011), aile sahipliği ve kurumsal sahipliğin temettü dağıtım politikası üzerinde etkisini incelemek amacıyla Çin'deki 1486 şirketin 2004-2008 dönemlerine ait finansal verilerini incelemişlerdir. Araştırma sonucunda şu üç sonuca ulaşmışlardır: 1. Aile şirketleri aile şirketi olmayanlara göre daha az temettü dağıtmaktadır. 2. Kurumsal sahiplik yapısındaki şirketler diğer şirketlere göre daha yüksek temettü dağıtım oranına sahiptir. 3. Kurumsal sahipliğin kâr dağıtım politikası üzerindeki etkisi aile şirketi olmayan şirketlerden daha fazladır.

Kang vd. (2010), Kore Borsası'na kote olan ve yabancı yatırımcısı bulunan şirketlerde yabancı sahipliğinin temettüye etkisini araştırmışlardır. Çalışmada, yabancı yatırımcıların sahiplik oranı $\% 5$ ya da daha fazla olan şirketlerin 2001-2007 yılları arasındaki finansal verileri incelenmiştir. Çalışmada, şirket hissesinin \% 5'ine sahip yabancı yatırımcıların temettü politikaları üzerinde etkisi olduğu tespit edilmiştir. Ayrıca yabancı kurumsal yatırımcıların sahip olduğu oran arttıkça ve yatırımcı sayısı önceki yıllara göre de arttıkça yabancı sahipliğin temettü üzerindeki etkisinin güçlendiği sonucuna ulaşmışlardır.

Ferreira ve Massa (2010), kâr dağıtım politikaları ile işletme sahipliği arasındaki ilişkiyi anlamak için 37 farklı ülkedeki holdinglerin 2007-2008 yılları arasındaki finansal verilerini incelemiştir. Yabancı kurumsal sahiplik yapısı ile temettü ödemesi ve temettü türleri arasında negatif ilişkinin tespit edildiği çalışmada yabancı yatırımcısı çok olan şirketlerin daha düşük miktarda kâr dağıtımı yaptığı, fonların çoğunluğunu şirkette tuttukları tespit edilmiştir.

Chai (2010), Kore'nin 1998 yılında dış ticaret ve finans alanındaki liberalizasyonu sonrasında Kore menşeli şirketlerin mülkiyet yapısı ile kâr dağıtımı arasındaki ilişkisini incelemiştir. Çalışma sonucunda, yabancı sahipliğin kâr dağıtımını pozitif yönde etkilediği tespit edilmiştir. Çalışmaya göre, bu şirketlerde yabancı yatırımcı sayısı arttıkça daha fazla temettü ödemesi yapıldığı da görülmektedir.

\section{2.ÇALIŞMANIN AMACI VE KAPSAMI}

Çalışmada BİST 50 Endeksi'nde kayıtlı olan ve 2015-2017 yılları arasında kâr dağıtımı yapmış olan şirketlerin sahiplik yapıları ile kâr dağıtım politikaları arasındaki ilişkinin araştırılması amaçlanmıştır. Kâr dağıtımı yapan şirketlerin sahiplik yapıları yıllar itibariyle Tablo 1'deki gibidir: 
Tablo 1. Şirketlerin Yıllar İtibariyle Sahiplik Kimlikleri

\begin{tabular}{|c|c|c|c|}
\hline \multirow{2}{*}{ Şirketler } & \multicolumn{3}{|c|}{ Şirketlerin Sahiplik Kimlikleri } \\
\hline & 2015 & 2016 & 2017 \\
\hline AEFES & Kurumsal Sahiplik & Kurumsal Sahiplik & Kurumsal Sahiplik \\
\hline AKBNK & Kurumsal Sahiplik & Kurumsal Sahiplik & Kurumsal Sahiplik \\
\hline ANACM & Kurumsal Sahiplik & Kurumsal Sahiplik & Kurumsal Sahiplik \\
\hline ARCLK & Kurumsal Sahiplik & Kurumsal Sahiplik & Kurumsal Sahiplik \\
\hline ASELS & Kurumsal Sahiplik & Kurumsal Sahiplik & Kurumsal Sahiplik \\
\hline BIMAS & Kurumsal Sahiplik & Kurumsal Sahiplik & Kurumsal Sahiplik \\
\hline CCOLA & Kurumsal Sahiplik & Kurumsal Sahiplik & Kurumsal Sahiplik \\
\hline CIMSA & Kurumsal Sahiplik & Kurumsal Sahiplik & Kurumsal Sahiplik \\
\hline ECILC & Kurumsal Sahiplik & Kurumsal Sahiplik & Kurumsal Sahiplik \\
\hline EKGYO & Kamu Sahipliği & Kamu Sahipliği & Kamu Sahipliği \\
\hline ENKAI & Yabancı Sahiplik & Yabanc1 Sahiplik & Yabancı Sahiplik \\
\hline EREGL & Kurumsal Sahiplik & Kurumsal Sahiplik & Kurumsal Sahiplik \\
\hline FROTO & Yabancı Sahiplik & Yabanc1 Sahiplik & Yabancı Sahiplik \\
\hline GARAN & Yabancı Sahiplik & Yabancı Sahiplik & Yabancı Sahiplik \\
\hline HALKB & Kamu Sahipliği & Kamu Sahipliği & Kamu Sahipliği \\
\hline ISCTR & Kurumsal Sahiplik & Kurumsal Sahiplik & Kurumsal Sahiplik \\
\hline ISDMR & Kurumsal Sahiplik & Kurumsal Sahiplik & Kurumsal Sahiplik \\
\hline KCHOL & Kurumsal Sahiplik & Kurumsal Sahiplik & Kurumsal Sahiplik \\
\hline KOZAL & Kurumsal Sahiplik & Kurumsal Sahiplik & Kurumsal Sahiplik \\
\hline MAVI & Aile Sahipliği & Aile Sahipliği & Aile Sahipliği \\
\hline OTKAR & Kurumsal Sahiplik & Kurumsal Sahiplik & Kurumsal Sahiplik \\
\hline PETKM & Yabanc1 Sahiplik & Yabanc1 Sahiplik & Yabancı Sahiplik \\
\hline SAHOL & Kurumsal Sahiplik & Kurumsal Sahiplik & Kurumsal Sahiplik \\
\hline SASA & Kurumsal Sahiplik & Kurumsal Sahiplik & Kurumsal Sahiplik \\
\hline SISE & Kurumsal Sahiplik & Kurumsal Sahiplik & Kurumsal Sahiplik \\
\hline SODA & Kurumsal Sahiplik & Kurumsal Sahiplik & Kurumsal Sahiplik \\
\hline TAVHL & Yabancı Sahiplik & Yabanc1 Sahiplik & Yabanc1 Sahiplik \\
\hline TCELL & Kurumsal Sahiplik & Kurumsal Sahiplik & Kurumsal Sahiplik \\
\hline TKFEN & Aile Sahipliği & Aile Sahipliği & Aile Sahipliği \\
\hline TOASO & Yabanc1 Sahiplik & Yabancı Sahiplik & Yabanc1 Sahiplik \\
\hline TRKCM & Kurumsal Sahiplik & Kurumsal Sahiplik & Kurumsal Sahiplik \\
\hline TSKB & Kurumsal Sahiplik & Kurumsal Sahiplik & Kurumsal Sahiplik \\
\hline TTKOM & Kurumsal Sahiplik & Kurumsal Sahiplik & Kurumsal Sahiplik \\
\hline TUPRS & Kurumsal Sahiplik & Kurumsal Sahiplik & Kurumsal Sahiplik \\
\hline ULKER & Kurumsal Sahiplik & Kurumsal Sahiplik & Yabanc1 Sahiplik \\
\hline VAKBN & Kamu Sahipliği & Kamu Sahipliği & Kamu Sahipliği \\
\hline VESBE & Kurumsal Sahiplik & Kurumsal Sahiplik & Kurumsal Sahiplik \\
\hline YKBNK & Kurumsal Sahiplik & Kurumsal Sahiplik & Kurumsal Sahiplik \\
\hline
\end{tabular}




\subsection{Araştırmanın Kısıtları}

Araştırma BİST 50 şirketlerini incelemesine rağmen, bazı şirketlerin belirtilen yıllar arasında hiç kâr dağıtımı yapmaması sebebiyle 38 şirket incelenebilmiştir. Başlangıç olarak 2013-2017 yıllarının incelenmesi amaçlansa da 2013-2015 yılları arasında sahiplik yapılarında değişiklik olmaması sebebiyle uygulama anlamlı sonuçlar vermemiş, bunun yerine 2015-2017 y1lı verileri incelenmiştir.

\subsection{Araştırmanın Yöntemi ve Veri Seti}

Araştırmada panel veri analizi kullanılmıştır. Zaman kesiti verileri olarak 2015, 2016 ve 2017 yılları; kesit verileri olarak ise kâr dağıtımı yapan 38 şirket verisi kullanılmıştır.

\subsection{Araştırmada Kullanılan Değişkenler}

Araştırmada kullanılan değişkenleri, bağımsız değişken olarak sahiplik yapısı değişkenleri, bağımlı değişken olarak kâr dağıtımı politikası değişkenleri ve kontrol değişkenleri olmak üzere üç grupta toplamak mümkündür.

Sahiplik yapısı değişkenleri ise sahiplik yoğunluğu ve sahiplik kompozisyonu olmak üzere iki gruba ayrılmıştır.

Sahiplik yoğunluğu değişkenleri Tablo 2'de gösterildiği şekildedir:

Tablo 2. Değişkenlerin Açıklamaları ve Veri Kaynağı

\begin{tabular}{|c|c|c|}
\hline Değişken & Açılaması & Literatür \\
\hline HAO & Halka Açıklık Oranı & $\begin{array}{c}\text { Özvar (2015), Güngör (2012), BAYRAKDAROĞLU (2010), Alövsat } \\
\text { (2002), Acaravcı vd (2015), Feng vd. (2009) }\end{array}$ \\
\hline EB1O & $\begin{array}{c}\text { En Büyük Ortağın } \\
\text { İşletmedeki Hisse Oranı }\end{array}$ & $\begin{array}{c}\text { Mancinelli ve Ozkan. (2006), Thanh ve Heaney (2007), Benjamin ve } \\
\text { Pajuste (2002), Klaus ve Yurtoglu (2003), Bayrakdaroğlu (2010), } \\
\text { Aydın ve Taşci (2010), Christian (2008), }\end{array}$ \\
\hline EB2O & $\begin{array}{c}\text { En İki Büyük Ortağın } \\
\text { İşletmedeki Hisse Oranı }\end{array}$ & Mancinelli ve Ozkan. (2006), Thanh ve Heaney (2007) \\
\hline EB3O & $\begin{array}{c}\text { En Üç Büyük Ortağın } \\
\text { İşletmedeki Hisse Oranı }\end{array}$ & Özvar (2015), Güngör (2012), Toraman ve Okuyan (2009) \\
\hline
\end{tabular}

Sahiplik kompozisyon değişkenleri Tablo 3’te gösterildiği şekildedir:

\section{Tablo 3. Değişkenlerin Açıklamaları ve Veri Kaynağı}

\begin{tabular}{|c|c|c|}
\hline Değişken & Açıklaması & Literatür \\
\hline Kurumsal & $\begin{array}{c}\text { Şirket kurumsal } \\
\text { sahiplikte ise 1, diğer } \\
\text { durumda 0 değerini alan } \\
\text { kukla değişken }\end{array}$ & Ünlü vd. (2017), Asquith vd. (2005), Rajeswararao ve Damanpour \\
(1991), Helen vd. (2002)
\end{tabular}


Kâr dağıtım politikası değişkeni Tablo 4'te gösterildiği şekildedir:

Tablo 4. Değişkenlerin Açıklamaları ve Veri Kaynağı

\begin{tabular}{|c|c|c|}
\hline Değişken & Açıklaması & Literatür \\
\hline \multirow{2}{*}{ NTO } & Nakit Temettü Oranı & Ege ve Bayrakdaroğlu (2009), Ersoy ve Çetenak (2015), Demirel \\
& & (2014) \\
\hline
\end{tabular}

Kontrol değişkenleri Tablo 5’te gösterildiği şekildedir:

Tablo 5. Değişkenlerin Açıklamaları ve Veri Kaynağı

\begin{tabular}{|c|c|c|}
\hline Değişken & Açıklaması & Literatür \\
\hline ROA & Aktif Kârlııı Oranı & Ramli (2010), Güngör (2012), Özvar (2015), Ersoy ve Çetenak (2015) \\
\hline ROE & $\begin{array}{c}\text { Öz Sermaye Kârlılık } \\
\text { Oranı }\end{array}$ & Ullah vd. (2010) \\
\hline FK & Finansal Kaldıraç Oranı & Özvar (2015), Ersoy ve Çetenak (2015) \\
\hline
\end{tabular}

Kullanılan değişkenlerin tanımlayıcı istatistikleri ise Tablo 6'da gösterilmiştir:

Tablo 6. Değisskenlerin Tanımlayıcı İstatistikleri

\begin{tabular}{|c|c|c|c|c|c|c|}
\hline Değisşken & & Ortalama & Std. Sapma & Minimum & Maksimum & Gözlem \\
\hline \multirow{3}{*}{ NTO } & Toplam & 62.293 & 103.837 & 3 & 650 & $\mathrm{~N}=$ \\
\hline & Gruplar aras 1 & & 112.069 & 3.933 & 635.9 & $\mathrm{n}=$ \\
\hline & Grupiçi & & 14.085 & 0.293 & 111.293 & T-bar $=2.605$ \\
\hline \multirow{3}{*}{ HAO } & Toplam & 34.149 & 14.819 & 5.380 & 72.59 & $\mathrm{~N}=104$ \\
\hline & Gruplar aras 1 & & 15.196 & 5.380 & 72.59 & $\mathrm{n}=38$ \\
\hline & Grupiçi & & 3.529 & 12.896 & 51.463 & T-bar $=2.736$ \\
\hline \multirow{3}{*}{ EB1O } & Toplam & 51.344 & 17.124 & 14.780 & 94.62 & $\mathrm{~N}=104$ \\
\hline & Gruplar aras 1 & & 16.941 & 14.893 & 94.62 & $\mathrm{n}=$ \\
\hline & Grupiçi & & 3.756 & 37.237 & 73.877 & T-bar $=2.736$ \\
\hline \multirow{3}{*}{ EB2O } & Toplam & 59.622 & 1717.006 & 2.100 & 85.9 & $\mathrm{~N}=92$ \\
\hline & Gruplar aras 1 & & 16.676 & 3.380 & 85.567 & $\mathrm{n}=$ \\
\hline & Grupiçi & & 2.750 & 50.019 & 72.452 & T-bar $=2.787$ \\
\hline \multirow{3}{*}{ EB3O } & Toplam & 67.603 & 9.801 & 51.710 & 87 & $\mathrm{~N}=$ \\
\hline & Gruplar aras 1 & & 9.885 & 51.710 & 85.265 & $\mathrm{n}=$ \\
\hline & Grupiçi & & 1.530 & 63.797 & 74.587 & $\mathrm{~T}=2.571$ \\
\hline \multirow{3}{*}{ ROA } & Toplam & $\begin{array}{l}0.057 \\
\end{array}$ & 0.050 & $\begin{array}{l}-0.088 \\
\end{array}$ & 0.178 & $\mathrm{~N}=114$ \\
\hline & Gruplar aras 1 & & 0.047 & -0.046 & 0.167 & $\mathrm{n}=\quad 38$ \\
\hline & Grupiçi & & 0.019 & 0.009 & 0.124 & $\mathrm{~T}=$ \\
\hline \multirow{3}{*}{ ROE } & Toplam & 0.147 & 0.115 & -0.242 & 0.403 & $\mathrm{~N}=114$ \\
\hline & Gruplar aras 1 & & 0.103 & -0.147 & 0.361 & $\mathrm{n}=\quad 38$ \\
\hline & Grupiçi & & 0.052 & -0.136 & 0.327 & $\mathrm{~T}=$ \\
\hline$\overline{\text { FK }}$ & Toplam & 0.596 & 0.232 & 0.078 & 0.917 & $\mathrm{~N}=114$ \\
\hline
\end{tabular}




\begin{tabular}{cccccc}
\hline Gruplar aras1 & 0.233 & 0.095 & 0.911 & $\mathrm{n}=$ & 38 \\
\hline Grupiçi & 0.024 & 0.524 & 0.694 & $\mathrm{~T}=$ & 3 \\
\hline
\end{tabular}

Değişkenlere ait tanımlayıcı istatistikler Tablo 6'da yer almaktadır. NTO değişkeninin ortalaması 62.293 olup minimum 3, maksimum 650 değeri arasında değişmektedir. Buna paralel olarak NTO değişkeninin standart sapma değeri de 103.837 'dir. Gruplar arası ve grup içi minimum ve maksimum değeri arasındaki farklar da NTO değişkeni için oldukça yüksektir. HAO değişkeninin de NTO değişkenine benzer olarak minimum ve maksimum değerleri arasındaki farklar, dolayısıyla standart sapmalar da oldukça yüksektir. EB1O, EB2O ve EB3O değişkeni için de durum aynı olduğu için değişkenlerin doğal logaritması alınıp ${ }^{2}$ analizlere devam edilmiştir. Kontrol değişkenleri olan ROA, ROE ve FK hem oran cinsinden olduğu için hem de minimum ve maksimum değerleri arasındaki farkın kabul edilebilir sınırlarda olduğu için analizlere düzey değerleri ile devam edilmiştir.

Tablo 7. Doğal Logaritması Alınan Değişkenlerin Tanımlayıcı İstatistikleri

\begin{tabular}{|c|c|c|c|c|c|c|}
\hline Değişken & & Ortalama & Std. Sapma & Minimum & Maksimum & Gözlem \\
\hline \multirow{3}{*}{ LNTO } & Toplam & 3.393 & 1.167 & 1.099 & 6.477 & $\mathrm{~N}=99$ \\
\hline & Gruplar aras1 & & 1.145 & 1.351 & 6.455 & $\mathrm{n}=$ \\
\hline & Grupiçi & & 0.313 & 2.246 & 4.078 & $\mathrm{~T}-\mathrm{bar}=2.605$ \\
\hline \multirow{3}{*}{ LHAO } & Toplam & 3.414 & 0.531 & 1.683 & 4.285 & $\mathrm{~N}=104$ \\
\hline & Gruplar aras1 & & 0.521 & 1.683 & 4.285 & $\mathrm{n}=$ \\
\hline & Grupiçi & & 0.141 & 2.591 & 4.151 & $\mathrm{~T}$-bar $=2.736$ \\
\hline \multirow{3}{*}{ LEB1O } & Toplam & 3.877 & "0.370 & 2.693 & "4.550 & $\mathrm{N}=104$ \\
\hline & Gruplar aras1 & & 0.364 & 2.701 & 4.550 & $\mathrm{n}=$ \\
\hline & Grupiçi & & 0.081 & 3.511 & 4.267 & $\mathrm{~T}-\mathrm{bar}=2.736$ \\
\hline \multirow{3}{*}{ LEB2O } & Toplam & 3.996 & 0.580 & 0.742 & 4.453 & $\mathrm{~N}=$ \\
\hline & Gruplar aras1 & & 0.563 & 1.175 & 4.449 & $\mathrm{n}=\quad 33$ \\
\hline & Grupiçi & & 0.072 & 3.563 & 4.221 & $\mathrm{~T}-\mathrm{bar}=2.787$ \\
\hline \multirow{3}{*}{ LEB3O } & Toplam & 4.203 & 0.149 & 3.946 & 4.466 & $\mathrm{~N}=$ \\
\hline & Gruplar aras1 & & 0.149 & 3.946 & 4.446 & $\mathrm{n}=$ \\
\hline & Grupiçi & & 0.020 & 4.154 & 4.292 & $\mathrm{~T}=2.571$ \\
\hline
\end{tabular}

\subsection{Araştırmada Test Edilen Hipotezler}

\section{Hipotez 1:}

$\mathrm{H}_{0}$ : En Büyük Ortağın Sermayedeki Payı (EB1O) ve sahiplik kompozisyonu ile Nakit Temettü Oranı (NTO) arasında bir ilişki yoktur.

$\mathrm{H}_{1}$ : En Büyük Ortağın Sermayedeki Payı (EB1O) ve sahiplik kompozisyonu ile Nakit Temettü Oranı (NTO) arasında bir ilişki vardır.

\section{Hipotez 2:}

$\mathrm{H}_{0}$ : En Büyük İki Ortağın Sermayedeki Payı (EB2O) ve sahiplik kompozisyonu ile Nakit Temettü Oranı (NTO) arasında bir ilişki yoktur.

$\mathrm{H}_{1}$ : En İki Büyük Ortağın Sermayedeki Payı (EB2O) ve sahiplik kompozisyonu ile Nakit Temettü Oranı (NTO) arasında bir ilişki vardır.

\section{Hipotez 3:}

$\mathrm{H}_{0}$ : En Büyük Üç Ortağın Sermayedeki Payı (EB3O) ve sahiplik kompozisyonu ile Nakit Temettü Oranı (NTO) arasında bir ilişsi yoktur.

$\mathrm{H}_{1}$ : En Büyük Üç Ortağın Sermayedeki Payı (EB3O) ve sahiplik kompozisyonu ile Nakit Temettü Oranı (NTO) arasında bir ilişki vardır.

${ }^{2}$ NTO, HAO, EB1O, EB2O ve EB3O için doğal logaritması alınan değişkenlerin analizin bu bölümünden sonraki gösterimi, sırasıyla, LNTO, LHAO, LEB1O, LEB2O v LEB3O şeklindedir. 


\section{Hipotez 4.1:}

$\mathrm{H}_{0}$ : Halka Açıklık Oranı (HAO) ve sahiplik kompozisyonu ile Nakit Temettü Oranı (NTO) arasında bir ilişki yoktur.

$\mathrm{H}_{1}$ : Halka Açıklık Oranı (HAO) ve sahiplik kompozisyonu ile Nakit Temettü Oranı (NTO) arasında bir ilişki vardır.

\section{Hipotez 4.2:}

$\mathrm{H}_{0}$ : Halka Açıklık Oranı (HAO), En Büyük Ortağın Sermayedeki Payı (EB1O) ve sahiplik kompozisyonu ile Nakit Temettü Oranı (NTO) arasında bir ilişki yoktur.

$\mathrm{H}_{1}$ : Halka Açıklık Oranı (HAO), En Büyük Ortağın Sermayedeki Payı (EB1O) ve sahiplik kompozisyonu ile Nakit Temettü Oranı (NTO) arasında bir ilişki vardır.

\section{Hipotez 4.3:}

$\mathrm{H}_{0}$ : Halka Açıklık Oranı (HAO), En Büyük İki Ortağın Sermayedeki Payı (EB2O) ve sahiplik kompozisyonu ile Nakit Temettü Oranı (NTO) arasında bir ilişki yoktur.

$\mathrm{H}_{1}$ : Halka Açıklık Oranı (HAO), En Büyük İki Ortağın Sermayedeki Payı (EB2O) ve sahiplik kompozisyonu ile Nakit Temettü Oranı (NTO) arasında bir ilişki vardır.

\section{Hipotez 4.4:}

$\mathrm{H}_{0}$ : Halka Açıklık Oranı (HAO), En Büyük Üç Ortağın Sermayedeki Payı (EB3O) ve sahiplik kompozisyonu ile Nakit Temettü Oranı (NTO) arasında bir ilişsi yoktur.

$\mathrm{H}_{1}$ : Halka Açıklık Oranı (HAO), En Büyük Üç Ortağın Sermayedeki Payı (EB3O) ve sahiplik kompozisyonu ile Nakit Temettü Oranı (NTO) arasında bir ilişki vardır.

\subsection{Araştırmada Oluşturulan Modeller}

Araştırmada test edilecek hipotezler için şu modeller oluşturulmuştur:
Model 1
$: N T O_{i t}=f\left(E B 10_{i t}, R O A_{i t}, R O E_{i t}, F K_{i t}\right.$, Aile $_{i t}, K$ Kamu $_{i t}$, Yabancl $\left._{i t}\right)$
Model 2
$: N T O_{i t}=f\left(E B 2 O_{i t}, R O A_{i t}, R O E_{i t}, F K_{i t}\right.$, Aile $_{i t}, K^{2}$ amu $i t$, Yabancl $\left._{i t}\right)$
Model 3
Model 4.1

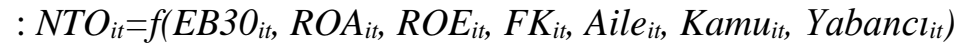
Model 4.2
Model 4.3
$: N T O_{i t}=f\left(H A O_{i t}, R O A_{i t}, R O E_{i t}, F K_{i t}\right.$, Aile $_{i}, K_{\text {Kamu }}$ it Yabancl $\left._{i t}\right)$
$: N T O_{i t}=f\left(H A O_{i t}, E B 10_{i t}, R O A_{i t}, R O E_{i t}, F K_{i t}\right.$, Aile $_{i t}, K_{\text {Kamu }}$, Yabancl $\left._{i t}\right)$
: NTO $O_{i t}=f\left(H A O_{i t}, E B 2 O_{i t}, R O A_{i t}, R O E_{i t}, F K_{i t}\right.$, Aile $_{i t}, K_{\text {Kamu }}$, Yabancl $\left._{i t}\right)$
Model 4.4
: NTO ${ }_{i t}=f\left(H A O_{i t}, E B 3 O_{i t}, R O A_{i t}, R O E_{i t}, F K_{i t}\right.$, Aile $_{i t}$, Kamu $_{i t}$, Yabancl $\left._{i t}\right)$

\subsection{Model Seçimi ve Uygulanacak Testler}

Modellerin ekonometrik tahminine geçilmeden önce, havuzlanmış, sabit ve rassal etkili modellerin seçiminde ilgili testler ve panel veri modellerinin aşamaları Şekil 1'de gösterilmiştir. $\mathrm{Bu}$ akış diyagramına göre; uygun model seçimi için F, LM ve Hausman testleri uygulanarak karar verilmiştir.

\section{Şekil 1: Panel Veri Modelleme Süreci}

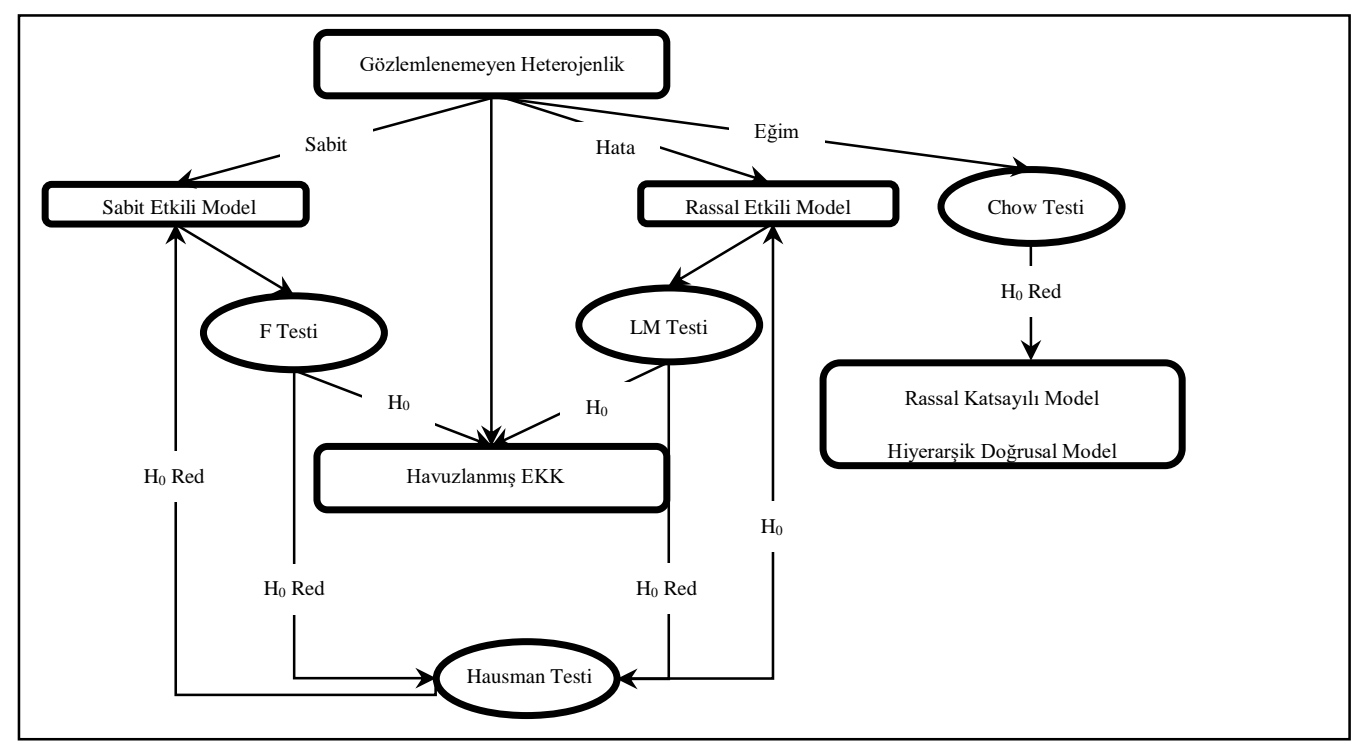

Kaynak: Park, H. M. (2011). Practical guides to panel data modeling: A step by step analysis using Stata. Public Management and Policy Analysis Program, Graduate School of International Relations, International University of Japan, 1-52. 
Analizin bu aşaması, panel veri analizi için uygun tahmin yönteminin seçilmesi aşamasıdır. Bu nedenle Model 1, Model 2, Model 3 ve Model 4 için havuzlanmış (pooled), sabit veya rassal etkili model seçimi için ilgili testler gerçekleştirilip sonuçları Tablo 9'de raporlanmıştır. Daha da açıklayıcı olması açısından, panel veri tahmin yöntemindeki hipotezler önce Tablo 8'de gösterilmiştir:

Tablo 8. Model Seçiminde Test edilen Hipotezler ve Uygun Testler

\begin{tabular}{l|c}
\hline \multicolumn{1}{c|}{ Hipotez } & Kullanılan Test \\
\hline $\mathrm{H}_{0}:$ Havuzlanmış model geçerlidir. & F Testi \\
$\mathrm{H}_{\mathrm{a}}:$ Sabit etkili model geçerlidir. & LM Testi \\
\hline $\mathrm{H}_{0}:$ Havuzlanmış model geçerlidir. & \\
$\mathrm{H}_{\mathrm{a}}:$ Rassal etkili model geçerlidir. & Hausman Testi \\
\hline $\mathrm{H}_{0}:$ Rassal etkili model geçerlidir. & \\
$\mathrm{H}_{\mathrm{a}}:$ Sabit etkili model geçerlidir. & \\
\hline
\end{tabular}

Tablo 9'daki sonuçlara göre, F testi havuzlanmış modelin geçersiz olduğunu, tüm modeller için reddedilip sabit etkili modelin tahmin yöntemi olarak kullanılması gerektiğini göstermektedir. Diğer taraftan LM testi, tüm modeller için rassal etkili modelin tahmin yöntemi olarak kullanılmasını öngörmektedir. Son olarak rassal etkili model ya da sabit etkili model arasında hangisinin geçerli olacağını gösteren Hausman testi sonuçlarına göre, tüm modeller için $\mathrm{H}_{0}$ hipotezinin kabul edilip rassal etkili modelin tahmin yöntemi olarak kullanılmas1 gerektiğini göstermektedir. Dolayısıyla analizin tahmin yönteminde, tüm modeller için rassal etkili model kullanılmış olup tahmin sonuçları Tablo 10'da gösterilmiştir.

Tablo 9. Panel Veri Tahmin Yöntemi Sonuçları

\begin{tabular}{ccccc}
\hline & $\boldsymbol{F}$ & $\boldsymbol{L M}$ & Hausman & Karar \\
\hline Model 1 & 17.47 & 59.26 & 4.43 & Rassal Etkili Model \\
Model 2 & $(0.000)^{*}$ & $(0.000)$ & $(0.488)$ & Rassal Etkili Model \\
& 18.02 & 42.84 & 6.32 & \\
Model 3 & $(0.000)$ & $(0.000)$ & $(0.276)$ & Rassal Etkili Model \\
& 14.40 & 15.45 & 4.19 & Rassal Etkili Model \\
Model 4.1 & $(0.000)$ & $(0.000)$ & $(0.381)$ & Rassal Etkili Model \\
Model 4.2 & 18.69 & 60.85 & 3.91 & \\
& $(0.000)$ & $(0.000)$ & $(0.563)$ & Rassal Etkili Model \\
Model 4.3 & 16.95 & 56.59 & 4.72 & Rassal Etkili Model \\
\hline
\end{tabular}

*Parantez içindeki değerler, olasılık değerleridir.

\subsection{Uygulama Sonuçları}

Tablo 10. Rassal Etkili Model Tahmin Sonuçları

\begin{tabular}{|c|c|c|c|c|c|c|c|}
\hline & Model 1 & Model 2 & Model 3 & Model 4.1 & Model 4.2 & Model 4.3 & Model 4.4 \\
\hline Sabit & $\begin{array}{c}\text { 5.946* }^{*} \\
(0.000)^{\S}\end{array}$ & $\begin{array}{l}3.914 * \\
(0.000)\end{array}$ & $\begin{array}{l}-2.754 \\
(0.765)\end{array}$ & $\begin{array}{l}2.598 * \\
(0.001)\end{array}$ & $\begin{array}{l}5.205 * \\
(0.000)\end{array}$ & $\begin{array}{l}2.743 * \\
(0.000)\end{array}$ & $\begin{array}{c}-12.676 * * \\
(0.015)\end{array}$ \\
\hline$\angle E B 1 O$ & $\begin{array}{c}-0.660 * * \\
(0.018)\end{array}$ & - & - & 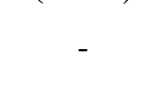 & $\begin{array}{c}-0.571 * * \\
(0.040)\end{array}$ & - & ( \\
\hline$\angle E B 2 O$ & - & $\begin{array}{l}-0.130 \\
(0.553)\end{array}$ & - & - & - & $\begin{array}{c}-0.116 * * * \\
(0.051)\end{array}$ & - \\
\hline$\angle E B 3 O$ & - & - & $\begin{array}{c}1.366 \\
(0.543)\end{array}$ & - & - & - & $\begin{array}{c}2.677 * * * \\
0.051)\end{array}$ \\
\hline LHAO & - & - & - & $\begin{array}{c}0.271 \\
(0.180)\end{array}$ & $\begin{array}{c}0.128 \\
(0.602)\end{array}$ & $\begin{array}{c}0.343 \\
(0.837)\end{array}$ & $\begin{array}{l}1.518 * \\
(0.007)\end{array}$ \\
\hline
\end{tabular}




\begin{tabular}{|c|c|c|c|c|c|c|c|}
\hline$R O A$ & $\begin{array}{c}0.068 \\
(0.976)\end{array}$ & $\begin{array}{c}-0.324 \\
(0.892)\end{array}$ & $\begin{array}{l}13.165 \\
(0.196)\end{array}$ & $\begin{array}{l}-0.435 \\
(0.851)\end{array}$ & $\begin{array}{c}-0.031 \\
(0.989)\end{array}$ & $\begin{array}{l}-0.491 \\
(0.837)\end{array}$ & $\begin{array}{c}8.865 \\
(0.308)\end{array}$ \\
\hline$R O E$ & $\begin{array}{c}0.535 \\
(0.489)\end{array}$ & $\begin{array}{c}0.942 \\
(0.155)\end{array}$ & $\begin{array}{l}-8.165 \\
(0.213)\end{array}$ & $\begin{array}{c}0.679 \\
(0.345)\end{array}$ & $\begin{array}{c}0.549 \\
(0.469)\end{array}$ & $\begin{array}{c}1.080 * * * \\
(0.091)\end{array}$ & $\begin{array}{c}-4.824 \\
(0.390)\end{array}$ \\
\hline$F K$ & $\begin{array}{c}0.141 \\
(0.836)\end{array}$ & $\begin{array}{c}0.105 \\
(0.895)\end{array}$ & $\begin{array}{c}0.953 \\
(0.563)\end{array}$ & $\begin{array}{l}-0.072 \\
(0.915)\end{array}$ & $\begin{array}{c}0.087 \\
(0.898)\end{array}$ & $\begin{array}{l}-0.0325 \\
(0.968)\end{array}$ & $\begin{array}{c}-0.526 \\
(0.789)\end{array}$ \\
\hline Aile & $\begin{array}{c}-0.731 \\
(0.191)\end{array}$ & $\begin{array}{c}-0.921 * \\
(0.004)\end{array}$ & $\begin{array}{c}1.127 \\
(0.323)\end{array}$ & $\begin{array}{l}-0.437 \\
(0.360)\end{array}$ & $\begin{array}{l}-0.749 \\
(0.171)\end{array}$ & $\begin{array}{l}-1.039 * \\
(0.001)\end{array}$ & $\begin{array}{c}0.436 \\
(0.680)\end{array}$ \\
\hline Кати & $\begin{array}{c}-1.216 * \\
(0.002)\end{array}$ & $\begin{array}{c}-1.568 * \\
(0.000)\end{array}$ & $\begin{array}{c}-1.967 * \\
(0.001)\end{array}$ & $\begin{array}{c}-1.372 * \\
(0.001)\end{array}$ & $\begin{array}{c}-1.271 * \\
(0.001)\end{array}$ & $\begin{array}{c}-1.644 * \\
(0.000)\end{array}$ & $\begin{array}{c}-2.149 * \\
(0.001)\end{array}$ \\
\hline Yabancl & $\begin{array}{c}-0.005 \\
(0.985)\end{array}$ & $\begin{array}{c}-0.034 \\
(0.911)\end{array}$ & $\begin{array}{c}0.421 \\
(0.479)\end{array}$ & $\begin{array}{l}-0.031 \\
(0.918)\end{array}$ & $\begin{array}{c}-0.008 \\
(0.975)\end{array}$ & $\begin{array}{c}0.002 \\
(0.996)\end{array}$ & $\begin{array}{c}0.401 \\
(0.549)\end{array}$ \\
\hline$R^{2}$ & 0.197 & 0.154 & 0.211 & 0.115 & 0.185 & 0.188 & 0.241 \\
\hline Wald $\chi^{2}$ & $\begin{array}{c}22.82 \\
(0.002)\end{array}$ & $\begin{array}{c}29.10 \\
(0.000)\end{array}$ & $\begin{array}{c}5.16 \\
(0.641)\end{array}$ & $\begin{array}{c}16.49 \\
(0.021)\end{array}$ & $\begin{array}{c}23.36 \\
(0.002)\end{array}$ & $\begin{array}{c}51.17 \\
(0.000)\end{array}$ & $\begin{array}{c}9.70 \\
(0.286)\end{array}$ \\
\hline$N \times T$ & 99 & 89 & 36 & 99 & 99 & 89 & 36 \\
\hline
\end{tabular}

Tablo 10'da, tahmin edilen modellerin katsayıları yer almaktadır. Model 1'in tahmin sonuçlarına göre, diğer değişkenler sabitken LEB1O'daki \% 1 birimlik artış, LNTO değişkenini \% 0,66 birim azaltmaktadır.

Şirketlerin sahipliğine ilişkin katsayı tahmin sonuçlarına göre, aile ve yabancı sahiplikte olan şirketlerin kurumsal şirketlere göre istatistiksel olarak anlamlı bir farklılığ olmadığ 1 tespit edilmiştir. Ancak kamu sahipliğine sahip şirketlerin kurumsal şirketlere göre LNTO'da 1.216 birim daha az olduğu sonucuna ulaşılmıştır. Modelin belirlilik katsayısı olan $\mathrm{R}^{2}$ değeri \% 19,7 olup Model 1 için LNTO'nun yaklaşı \% 20'si modeldeki değişkenler tarafından açıklanmaktadır. Ayrıca Wald $\chi^{2}$ testi sonuçları modelin geçerli olduğunu göstermektedir.

Model 2'nin tahmin sonuçlarına göre, LEB2O istatistiksel olarak anlamlı tahmin edilememiştir. Model 2'de istatistiksel olarak anlamlı olan katsayılar Aile ve Kamu değişkenleridir. Bunun anlamı, aile şirketlerinin kurumsal şirketlere göre LNTO farkı 0.921 birim daha az iken kamu şirketlerinin kurumsal şirketlere göre LNTO fark1 1.568 birim daha azdır. Modelin belirlilik katsayısı \% 15,4 olup Wald testine göre model istatistiksel olarak geçerlidir.

Model 3'ün tahmin sonuçları Model 2'ye benzer olup Model 2'den ayrıldığı nokta aile şirketlerinin kurumsal şirketlere göre istatistiksel olarak farklılaşmadığı ve Wald testine göre modelin geçersiz olduğudur.

Model 4.1'de, şirketlerin en büyük ortaklık oranları yerine halka açıklık oranları ile LNTO arasındaki ilişki yer almaktadır. Modelin belirlilik katsayıs1 \% 11,5 olup istatistiksel olarak geçerlidir. Ancak LHAO değişkeni istatistiksel olarak anlamsız olup, kamu sahipliğine ait olan şirketler kurumsal şirketlere göre LNTO'da 1.372 birim daha azdır.

Model 4.2'nin tahmin sonuçlarına göre, diğer değişkenler sabit iken LEB1O'daki \% 1 birimlik artış, LNTO'yu \% 0,571 birim azaltmaktadır. LHAO ise istatistiksel olarak anlamsız olup kontrol değişkenlerinden sadece Kamu değişkeni istatistiksel olarak anlamlıdır. Bir başka deyişle, kamu şirketlerinin kurumsal şirketlere göre LNTO farkı 1.271 birim daha azdır. Modelin belirlilik katsayısı \% 18,5 olup model istatistiksel olarak geçerlidir.

Model 4.3'ün tahmin sonuçlarına göre LEB2O, ROE Aile ve Kamu değişkenleri istatistiksel olarak anlamlı tahmin edilmiştir. LEB2O, Aile ve Kamu değişkenleri, diğer modellerle benzer olarak aynı etkiyi göstermektedir. Ancak LHAO değişkeni LEB2O ile LNTO üzerinde istatistiksel olarak anlamlı değildir.

Model 4.3'ün tahmin sonuçlarına göre, LHAO, LEB3O ile beraber LNTO üzerinde istatistiksel olarak anlamlı tahmin edilmiştir. Modelin belirlilik katsayısı, diğer modellere göre en yüksek değerde olup \% 24,1 değerindedir. Ancak istatistiksel olarak modelin geçerliliği, Wald testine göre anlamlı değildir. Model 3 ile Model 4.3'ün istatistiksel olarak geçersiz olmasının nedeni LEB3O değişkeninin yeterli gözlem değerine sahip olmaması olarak yorumlanabilir. Bu nedenle bu modellerin istatistiksel olarak anlamlı olabilmesi için örnek hacmi genişletilebilir.

Son olarak kontrol değişkenleri olan ROA, ROE ve FK istatistiksel olarak anlamlı sonuçlar vermemiştir. Dolayısıyla bağımlı değişken üzerindeki etkileri, tahmin edilen katsayı değeri kadar değildir.

\section{SONUÇ}

Şirketler likidite durumlarına göre ve finansal hedeflerine göre nakit olarak temettü dağıtmaktadır. Nakit olarak dağıtılan temettünün miktarının ve dağıtım sıklığının belirlenmesinde yasal mevzuat, ülke ekonomisi, şirket sözleşmeleri gibi değerlendirilmesi gereken faktörler vardır. Bunların yanında şirket içi dinamikler de kâr dağıtım politikalarını etkilemektedir. Şirketlerin sahiplik yapısı da bunlardan biridir. 
Daha önce yapılan araştırmalara bakıldığında, sahiplik yapısı ile kâr dağıtımı arasında negatif ve pozitif yönlü bir ilişki olduğunu ileri süren çalışmaların olduğu görülmektedir. Abdullah vd. (2012) sahiplik yoğunluğu ve kâr dağıtımı oranı arasında pozitif yönlü ilişki olduğunu tespit etmiştir. Şirket hisseleri daha az kişi arasında bölüştürüldüğü zaman şirket daha fazla kâr dağıtımı yapmaktadır. Ting'e göre (2017) sahiplik yoğunluğu arttıkça kâr dağıtımı azalmaktadır. Diğer bir ifadeyle sahiplik yoğunluğu ile kâr dağıtımı arasında negatif yönlü bir ilişki vardır.

Arshad vd. (2013) yaptıkları çalışmada sahiplik yoğunluğu ve temettü oranı arasında negatif ya da pozitif yönlü herhangi bir bir ilişki tespit edememişlerdir.

Sahiplik yoğunluğu ile temettü dağıtım arasında hem pozitif hem de negatif yönlü ilişkinin bulunması, araştırılan şirketlerin homojen olmamasına ve farklı sektörlerde faaliyet gösteren şirketler üzerinde analizlerin yapılmasına bağlanabilir. Aynı sektörde faaliyet gösteren şirketler üzerinde çalışıldığında ve şirketler kendi aralarında küçük gruplara bölündüğünde ise daha anlamlı sonuçlar elde edilecektir. Nitekim Ersoy ve Çetenak (2015), şirketleri yavaş hızda büyüyen şirketler ve hızlı büyüyen şirketler olmak üzere iki gruba ayırdıkları çalışmalarında yavaş hızda büyüyen şirketlerde sahiplik yoğunluğu ile temettü oranı arasında anlamlı bir ilişki tespit edilemezken; hızlı büyüyen şirketlerde sahiplik yoğunluğunun nakit temettü oranını etkilediğini bulmuşlardır.

Bu çalışmada BİST 50 endeksinde kayıtlı olan ve 2015-2017 yılları arasında kâr dağıtım yapan şirketlerin sahiplik yapılarının kâr dağıtım politikalarına etkisi araştırılmıştır. Bu şirketlerin 2015-2017 yılları arasındaki sahiplik yapısı verileri ile kâr dağıtım verileri panel veri analizi yöntemi ile analiz edilmiştir.

Elde edilen sonuçlara göre;

En büyük ortağın sahip olduğu hisse oranı ile şirketin nakit temettü oranı arasında negatif yönlü ve anlamlı bir ilişki tespit edilmiştir. En büyük ortağın hissesinin \% 1 birimlik artması dağıtılan kârın \% 0,66 birim azalmasına neden olmaktadır. En büyük iki ortağın hisse oranı ve en büyük üç ortağın hisse oranı ile nakit temettü oranı arasında ise anlamlı bir ilişki tespit edilememesine rağmen ortak hissesinin artması sahiplik yoğunluğunun da artması anlamına geldiğinden dolayı sahiplik yoğunluğu ile kâr dağıtım oranı arasında negatif yönlü ilişkinin olduğu söylenebilir.

Aile işletmelerinde diğer bir ifadeyle yönetim ve kontrol hakkını elinde tutan kişiler aynı aile bireyleri olan işletmelerde, nakit kâr dağıtımı kurumsal şirketlere göre daha az oranlarda yapılmaktadır. Yine aynı şekilde kamu şirketleri de kurumsal şirketlere göre daha az oranda kâr dağıtımı yapmaktadır. Aile şirketleri ile kamu şirketleri kendi aralarında kıyaslandığında aile şirketlerinin daha fazla oranda kâr dağıttığı gözlemlenmiştir.

Çalışmanın bir diğer sonucuna göre; halka açıklık oranı ile temettü oranı arasında anlamlı olmayan negatif yönlü bir ilişki tespit edilmiştir. Halka açıklık oranının artması büyük ortakların hisse oranlarının azalması demektir. Dolayısıyla nakit temettü oranı, sahiplik yoğunluğu ve halka açıklık oranı karşısında ters yönde tepki vermesi beklenir. Bu da halka açıklık oranı ve nakit temettü arasında negatif yönlü ilişkinin anlamsız olduğunu desteklemektedir.

Elde olan elde edilen sonuçların istatistiksel olarak anlamlı olmaması örneklemin BİST 50 endeksinde seçilmesinden kaynaklanmaktadır. Gelecekte yapılacak çalışmalarda örneklemin aynı sektörlerde faaliyet gösteren şirketlerden seçilmesi ve dikey kesit verilerinin daha uzun dönemlerden oluşturulması analiz edilen değişkenlerin daha hassas ölçülmesine yardımcı olacaktır. 


\section{KAYNAKÇA}

Anderson, Ronald C. ve David, M. Reeb. (2003). Founding-family ownership and firm performance: evidence from the S\&P 500, The journal of finance, (58) 3, 1301-1328.

Andres, Christian (2008). Large shareholders and firm performance:An empirical examination of founding-family ownership, Journal Of Corporate Finance, (14) 4, 431-445.

Ang, James ve David, K. Ding (2006). Government ownership and the performance of government-linked companies: The case of Singapore, Journal of Multinational Financial Management, (16) 1, 64-88.

Arshad, Zeeshan. Akram, Yasir. Amjad, Maryam ve Usman, Muhammad (2013). Ownership Structure And Dividend Policy, Interdisciplinary Journal Of Contemporary Research In Business, 5 (3), 378-401.

Asquith, Paul, Parag A. Pathak ve Jay R. Ritter (2005). Short interest, institutional ownership, and stock returns, Journal of Financial Economics, (78) 2, 243-276.

Bayrakdaroğlu, Ali (2010). Mülkiyet Yapısı ve Finansal Performans: İMKB Örneği, Ekonomi Bilimleri Dergisi, 2 (2), 11-20.

Canbaş, Serpil ve Vural, Gamze (2012). Finansal Yönetim: Açıklamalı Örnekler ve Problemler, 2. Baskı, Adana: Karahan Kitabevi

Chaganti, Rajeswararao ve Fariborz Damanpour (1991). Institutional ownership, capital structure, and firm performance, Strategic management journal, (12) 7, 479-491.

Chhibber, Pradeep K., ve Sumit, K. Majumdar (1999). Foreign ownership and profitability: Property rights, control, and the performance of firms in Indian industry, The Journal of Law and Economics, (42) 1, 209-238.

Dahlquist, Magnus ve Göran, Robertsson (2001). Direct foreign ownership, institutional investors, and firm characteristics, Journal of financial economics, (59) 3, 413-440.

Davies, J. R., Hillier, David ve Mccolgan, Patrick (). Ownership Structure, Managerial Behavior And Corporate Value, SSRN Electronik Journal, 11 (4), 645-650.

Erdaş, Mehmet Levent (2017). Kâr Payı Dağıtım Politikasını Etkileyen İşletmelere Özgü Faktörlerin Belirlenmesi: Borsa İstanbul-30 Endeksi Üzerine Bir Uygulama, Journal Of Life Economics, 4 (2), 49-76.

Ersoy, Ersan ve Çetenak, Emin Hüseyin (2015). Sahiplik Yoğunlaşmasının Temettü Dağıtım Kararlarına Etkisi: Borsa İstanbulda Bir Uygulama, Ege Akademik Bakış Dergisi, 4 (15), 509-521

Ferreira, Miguel, Massa, Massimo ve Pedro Mtaos (2009). Dividend Clienteles Around The World: Evidence From Institutional Holdings, Marshall School Of Business Working Paper, (54)

Ghunmi, Diana Abu, Al-Zu'bi, Bashar, Badreddine, Sina ve Chaudhry, Shahid (2013). Foreign Direct Investments in Jordan, International Journal Of Business, 18 (3), 256-272.

Gugler, Klaus ve Yurtoglu, B. Burcin (2003). Corporate governance and dividend pay-out policy in Germany, European economic review, (47) 4, 731-758.

Güngör, Selim (2012). Sahiplik YapısıvVe Temettü İlişkisi: İMKB'de Bir Uygulama, Yüksek Lisans Tezi, Hitit Üniversitesi Sosyal Bilimler Enstitüsü, Çorum.

http://www.tdk.gov.tr/index.php?option=com_gts\&kelime=sahiplik (Erişim Tarihi: 01.09.2019)

Kakilli Acaravcı, Songül, Kandır, S. Yılmaz ve Zelka, Ahmet (2015). Kurumsal Yönetimin BíST Şirketlerinin Performanslarına Etkisinin Araştırılması, Niğde Üniversitesi İktisadi ve İdari Bilimler Fakültesi Dergisi, 8 (1), 171-183.

Kang, Shinae, Kim, Soojung ve Sul, Wonsik (2010). Impact Of Foreıgn Institutional Investors On Dividend Policy In Korea: A Stock Market Perspective, Journal Of Financial Management And Analysis, 23 ( L), 10-26.

Khan, Jan Shair, Ahsan, Syed Muhammad ve Malik, Hilal Ahmed (2015). Impact Of Ownership Structure On Dividend Policy And Capital Structure: Evidence From Non-Financial Sector Of Pakistan, Journal Of Management Info, 2(4), 16-25.

Lundgren, Bjorn, Lantz, Christofer Eriksson ve Lions, Catherine (2016). Ownership Structure's Effect On Dividend Policy Evidence From Publicly Listed Swedish Firms, Thesis, School Of Business And Economics, Sweden.

Mancinelli, Luciana ve Aydin, Ozkan (2006). Ownership structure and dividend policy: Evidence from Italian firms, European Journal of Finance, (12) 3, 265-282.

Manneh, Marwan (2014). Determinants Of Dividends Policy: Evidence From Non-Financial Companies Listed On Abu Dhabi Securities Exchange (ADX), Thesis, Cardiff School Of Management Cardiff Metropolitan University, Cardiff UK

Maury, Benjamin (2006). Family ownership and firm performance: Empirical evidence from Western European corporations, Journal of corporate finance, (12) 2, 321-341.

Müslümov, Alövsat (2002). Türkiye'de halka açılan KOBİ boyutunda işletmelerin büyük ölçekli işletmelerden farklılaşımı ve sermaye piyasalarının KOBİ'ler açısından önemi, Ege Akademik Bakış Dergisi, (8) 2, 519-540.

Okuyan, H. Aydın ve Taşcı, H. Mehmet (2010). Sermaye Yapısının Belirleyicileri: Türkiye'deki En Büyük 1000 Sanayi İşletmesinde Bir Uygulama, Journal of BRSA Banking \& Financial Markets, (4) 1.

Önem, Hüseyin Başar (2014). Kâr Dağıtım Kararlarının Ve Mülkiyet Yapısının Firma Performansına Etkisi: Bıst İmalat Sektörü Üzerine Bir Uygulama, Doktora Tezi, Süleyman Demirel Üniveristesi Sosyal Bilimler Enstitüsü, Isparta.

Özvar, Koray (2015). Sahiplik Yapısının Kâr Dağıtım Politikası Üzerine Etkisi: Borsa İstanbul'da Bir Uygulama, Yüksek Lisans Tezi, Nevşehir Hacı Bektaş Veli Üniversitesi Sosyal Bilimler Enstitüsü, Nevşehir. 
Qahtani, Tahani Hmood ve Ajına, Aymen (2017). The Impact Of Ownership Structure On Dividend Policy The Evidence From Saudi Arabia, Journal Of Emerging Issues in Economics, 6 (1), 2187-2202.

Ramli, N. Mazna (2010). Ownership Structure And Dividend Policy: Evidence From Malaysian Companies, International Review Of Business Research Papers, 6 (1), 170-180.

Reyna, Juan Manuel San Martin (2017). Ownership Structure And Its Effect On Dividend Policy in Mexican Context, Contaduria Y Administracion, (62), 1199-1213.

Sevimli Örgün, Gamze ve Aygün, Mehmet (2018). Sahiplik Yapısı ve Kâr Kalitesi: Borsa İstanbul Üzerine Bir İnceleme, Muhasebe Ve Vergi Uygulamaları Dergisi,11 (3), 333-348.

Short, Helen, Hao Zhang ve Kevin Keasey (2002). The link between dividend policy and institutional ownership, Journal of corporate Finance, (8) 2, 105-122.

Sun, Qian, Wilson, HS Tong ve Jing, Tong How does government ownership affect firm performance? Evidence from China's privatization experience, Journal of Business Finance \& Accounting, (29) 1, 1-27.

Ting, Irene Wei Kiong, Kwehb, Qian Long ve Somosundaram, Kausalyaa (2017). Ownership Concentration, Dividend Payout And Firm Performance: The Case Of Malaysia, Malaysian Journal Of Economic Studies, 54 (2), $269-280$.

Toraman, Cengiz ve Okuyan, H. Aydın (2009). İşletmelerde ortaklık yapısında yoğunlaşmanın kaynak yapısı üzerindeki etkisi: İMKB şirketleri üzerine bir uygulama, Muhasebe ve Finansman Dergisi, (41), 72-81.

Truong, Thanh ve Richard, Heaney (2007). Largest shareholder and dividend policy around the World, The Quarterly Review of Economics and Finance, (47) 5, 667-687.

Ullah, Hamid Fida, Asma ve Khan, Shafiullah (2012). The Impact Of Ownership Structure On Dividend Policy Evidence From Emerging Markets Kse-100 Index Pakistan, International Journal Of Business And Social Science, 3 (9), 298-307.

Uwuigbe, Uwalomwa (2012). An Examination Of The Effects Of Ownership Structure And Financial Leverage On The Dividend Policies Of Listed Firms in Nigeria, Journal Of Economics, Business, And Accountancy Ventura, 16 (2), 251-258.

Ünlü, Ulaş (2011). Yönetici Sahipliği ve Firma Değeri: İMKB İçin Ampirik Bir Uygulama, Ankara Üniversitesi SBF Dergisi, 66 (2), 201-214.

Warrad, Lina, Abed, Suzan-Khriasat, Ola ve Sheikh, Imad (2012). The Effect Of Ownership Structure On Dividend Payout Policy: Evdence From Jrdonian Context, International Journal Of Economics And Finance, 4 (2), 187-195.

Wei, Zhihua, Wu, Shinong, Li, Changqing ve Chen, Wei (2011). Family Control Instituonal Environment And Cash Dividend Policy: Evdence From China, China Journal Of Accounting Research, (4), 29-46.

Zhang, Feng, Yao, Tian ve Wirjanto, Tony S. (2009). Empirical tests of the float-adjusted return model, Finance Research Letters, (6) 4, 219-229. 